\title{
Favourable effects of whey protein on acetic acid-induced ulcerative colitis in a rat model
}

Nurettin Tunc ${ }^{1}$, Abdurahman Sahin², Ulvi Demirel2 ${ }^{2}$ Gokhan Artas' ${ }^{3}$, Kazım Sahin ${ }^{4}$, ibrahim Halil Bahcecioglu², Mehmet Yalniz ${ }^{2}$

\author{
${ }^{1}$ Department of Gastroenterology, Health Sciences University Gazi Yasargil Training \\ and Research Hospital, Diyarbakir, Turkey \\ ${ }^{2}$ Department of Gastroenterology, School of Medicine, Firat University, Elazig, Turkey \\ ${ }^{3}$ Department of Pathology, School of Medicine, Firat University, Elazig, Turkey \\ ${ }^{4}$ Department of Animal Nutrition, Faculty of Veterinary Science, Firat University, \\ Elazig, Turkey
}

Submitted: 31 December 2018; Accepted: 19 March 2019

Online publication: 21 March 2021

Arch Med Sci 2022; 18 (6): 1617-1625

DOI: https://doi.org/10.5114/aoms/105839

Copyright $\odot 2021$ Termedia \& Banach

\section{Abstract}

Introduction: In the present study, we aimed to examine the effects of the administration of whey protein through rectal enema to rats with acetic acid-induced ulcerative colitis on the pathways of nuclear-related factor-2 (Nrf-2), haem oxygenase-1 (HO-1), nuclear factor $\kappa B(N F-\kappa B)$, active protein kinase-1 (AP-1), tumour necrotising factor- $\alpha$ (TNF- $\alpha$ ), and cyclooxygenase- 2 (COX-2), IL-6, IL-10.

Material and methods: Twenty-eight rats were employed for the trial. Ulcerative colitis was induced through the use of acetic acid. The therapeutic doses of whey protein were administered rectally. Ulcerative colitis was subjected to histopathological examination and protein levels in colon tissue were measured with the Western blot method.

Results: The significant increases observed in the levels of AP-1, COX-2, IL-6, IL-10, NF- $\kappa B$, and TNF- $\alpha$ as markers of inflammation following the development of ulcerative colitis showed remarkable decreases along with the administration of whey protein $(p<0.05)$. On the other hand, we identified a decrease in the Nrf2-ARE signal pathway and HO-1 protein having protective roles in the colon inflammatory response along with the development of ulcerative colitis and activation of the Nrf2-HO-1 pathway by the whey protein.

Conclusions: Whey protein modulates Nrf2/HO-1 and NF-kB pathways, thereby creating a therapeutic effect against colonic inflammation induced by acetic acid (AA) due to its anti-inflammatory effects.

Key words: whey protein, Nrf2/HO-1, NF- $\mathrm{KB}$ pathway, acetic acid-induced ulcerative colitis.

\section{Introduction}

Inflammatory bowel diseases (IBD) are lifelong diseases, and have a significant impact on quality of life. Crohn's disease and ulcerative colitis (UC) are two idiopathic inflammatory bowel disorders [1]. UC is disease characterised by intestinal chronic inflammation and by a currently unclear aetiology. The pathophysiology of UC is multifactorial in nature and the basic factors are regarded to be increased oxidative stress and impaired immunomodulation [2]. In addition to the direct toxic effects of

\author{
Corresponding author: \\ Nurettin Tunc \\ Department of \\ Gastroenterology \\ Health Sciences \\ University Gazi Yasargil \\ Training and \\ Research Hospital \\ 21070 Diyarbakir \\ Turkey \\ E-mail: nurettin@firat.edu.tr
}


reactive metabolites, they have also been shown to have the potential to cause chronic intestinal inflammation by stimulating the synthesis of a number of inflammatory cytokines at the gene level as a result of the activation of nuclear factor- $\kappa \mathrm{B}(\mathrm{NF}-\kappa \mathrm{B})$ along with their effects on one or more redox-sensitive kinases [3]. A large number of antioxidant molecules already in use for the treatment of IBD have been shown to have beneficial effects on intestinal inflammation [4-6].

Whey protein is an end product of casein precipitation that occurs during the production of cheese. Whey protein has become a superfood by reason of its functionality and nutritional value [7]. A number of studies have established that whey protein exerts antihypertensive, immune-modulating, bacteriostatic, antioxidant, and free radical scavenging effects $[7,8]$. Whey protein has also been reported to be able to improve the regulation of Th1 and Th2 cytokine responses without any toxic effects [9]. All of these findings suggest that whey protein is promising as a tool for the treatment of UC as a cheap and safe alternative to currently administered expensive medicine with high potential for adverse effects.

The present study aimed to establish whether whey protein treatment administered through rectal enema in an acetic acid-induced ulcerative colitis rat model has therapeutic effects.

\section{Material and methods}

The protocol of this study was approved by the Firat University animal experiments local ethics committee (FUHAYEK). The female Wistar rats of 250-300 g in weight ( $n=28,6$ months of age) were sourced from the Experimental Research Centre (Elazig, Turkey) of Firat University to be employed for the study. The animals were sheltered at an average temperature of $21-22^{\circ} \mathrm{C}$ and under humidity of $55 \pm 5 \%$ in a cycle of $12 \mathrm{~h}$ of darkness and $12 \mathrm{~h}$ of light. All procedures required for the present study were implemented in compliance with the international principles of use and care of experimental animals and upon the approval of the Ethics Committee for Research with Laboratory Animals of Firat University. The rats were held in suitable cages with easy access to standard pellet feed and water. Rats were subject to fasting $24 \mathrm{~h}$ before the completion of the experiment.

\section{Experimental protocol (Table I)}

The rats were randomly divided into 4 groups and fasted $24 \mathrm{~h}$ before the start of the experimental procedure. The normal control $(n=7)$ group was fed with $2 \mathrm{ml}$ of saline every day. On the other hand, the acetic acid (AA) $(n=7)$ group was provided with $1.5 \mathrm{ml}$ of $5 \%$ AA once and with $2 \mathrm{ml}$ of saline every day. The AA + whey protein I (WPI) $(n=7)$ group was administered $1.5 \mathrm{ml}$ of $5 \%$ AA once followed by the feeding of a $2 \mathrm{ml}$ solution containing $2.39 \mathrm{~g} / \mathrm{kg}$ whey protein for rats once a day for 7 days as calculated at the dosage of $33.3 \mathrm{~g}$ recommended for the consumption of whey protein isolate by athletes as nutritional support in line with the table for the Conversion of Animal Doses to Human Equivalent Doses [10] of the Food and Drug Administration (FDA). The AA + WPII $(n=7)$ group was administered $1.5 \mathrm{ml}$ of $5 \%$ AA once followed by the feeding of a $2 \mathrm{ml}$-solution containing $2.39 \mathrm{~g} / \mathrm{kg}$ whey protein once a day for 7 days. A soft polyethylene catheter of $3 \mathrm{~mm}$ in diameter was placed at a maximum depth of $8 \mathrm{~cm}$ into the anuses of rats under ether anaesthesia; $1.5 \mathrm{ml}$ of $5 \% \mathrm{AA}$ and $2.39 \mathrm{~g} / \mathrm{kg}$ of $2 \mathrm{ml}$ whey protein were administered carefully with the rats in the Trendelenburg position. The catheter was removed after being kept in position for $15 \mathrm{~s}$.

Acetic acid (AA) was procured from Sigma-Aldrich Chemie $\mathrm{GmbH}$ Germany and whey protein (WP) (Premium Whey) from Weider Germany GmbH Hamburg.

The rats were decapitated under ether anaesthesia at the end of the $7^{\text {th }}$ day of the experiment (Figure $1 \mathrm{~A}$ ). Following the due opening of the abdomen, the colon was excised along a length of $10 \mathrm{~cm}$ starting from the rectum with proximal extension (Figure $1 \mathrm{~B}$ ). The distal piece of $2 \mathrm{~cm}$ was removed from the excised colon tissue and retained in $10 \%$ formaldehyde solution for histopathological examinations. The remaining colon segment was placed into aluminium foil and retained there at $-70^{\circ} \mathrm{C}$ until the testing date for the measurement of the levels of nuclear factor $\kappa \mathrm{B}(\mathrm{NF}-\kappa \mathrm{B})$, activated protein kinase-1 (AP-1), nuclear-related factor-2 (Nrf-2), tumour necrotising factor- $\alpha$ (TNF- $\alpha$ ), haem oxygenase (HO-1), and cyclooxygenase-2 (COX-2), IL-6, IL-10 in colon tissue with the Western blot method.

Table I. Experimental protocol of the study

\begin{tabular}{|lcccc|}
\hline Group & Control $(n=7)$ & AA $(n=7)$ & AA + WPI $(n=6)$ & AA + WPII $(n=5)$ \\
\hline Intra-colonic saline & + & + & - & + \\
\hline Intra-colonic AA & - & + & + & + \\
\hline Intra-colonic WP single dose & - & - & - & - \\
\hline Intra-colonic WP double dose & - & - & + \\
\hline
\end{tabular}



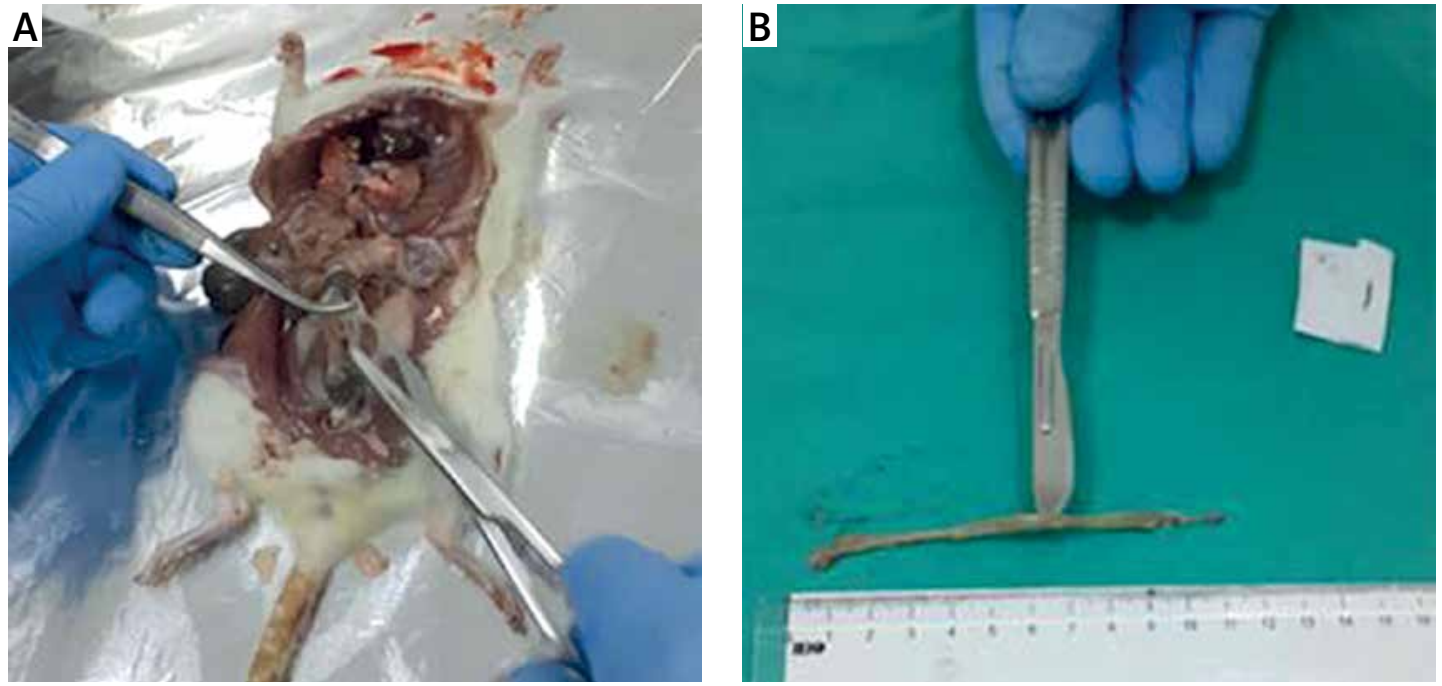

Figure 1. A - Distal colon after midline laparotomy in the control group. B - The colon was excised $10 \mathrm{~cm}$ starting from the rectum in the control group

\section{Laboratory analysis. Western blot}

Colon samples were analysed by the Western blot method for the expression of NF- $\mathrm{B}, \mathrm{AP}-1$, Nrf-2, TNF- $\alpha$, HO-1, COX-2, and IL-6, IL-10. Rat colons were removed in all groups. Smaller pieces of the colon samples collected from each group were gathered together for Western blot analysis. Protein extraction: The samples were homogenised in $1 \mathrm{ml}$ of hypotonic buffer A cooled in ice $(10 \mathrm{mM}$ HEPES (pH 7.8), $10 \mathrm{mM} \mathrm{KCl}, 2 \mathrm{mM}$ $\mathrm{MgCl}_{2}, 1 \mathrm{mM}$ DTT, $0.1 \mathrm{mM}$ EDTOA, and $0.1 \mathrm{mM}$ phenylmethanesulfonyl fluoride (PMSF)). $80 \mu \mathrm{l}$ of $10 \%$ Nonidet P-40 (NP-40) solution was added to the homogenates followed by centrifugation at $14000 \mathrm{~g}$ for $2 \mathrm{~min}$. The supernatant was collected as a cytosolic fraction for the analysis of $\mathrm{HO}-1$. The falling nuclei were washed once with $500 \mu \mathrm{l}$ of buffer A plus $40 \mu \mathrm{l}$ of $10 \%$ NP-40, centrifuged, and re-suspended with $200 \mu \mathrm{l}$ of buffer $\mathrm{C}$ (50 mM HEPES ( $\mathrm{pH} 7.8$ ), $50 \mathrm{mM} \mathrm{KCl}, 300 \mathrm{mM}$ $\mathrm{NaCl}, 0.1 \mathrm{mM}$ EDTA, $1 \mathrm{mM}$ DTT, $0.1 \mathrm{mM}$ PMSF, $20 \%$ glycerol) and then centrifuged at $14800 \mathrm{~g}$ for $5 \mathrm{~min}$. The supernatant containing nuclear proteins was collected for the analysis of $\mathrm{Nrf2}$ and NF- $\mathrm{B} B$ p65 [11]. The protein concentration was determined with a protein testing kit provided by Sigma, St. Louis, MO, USA in line with the procedure described by Lowry et al. [12]. The supernatant was complemented with a sodium dodecyl sulphate-polyacrylamide gel electrophoresis buffer containing a $2 \% \quad \beta$-mercaptoethanol sample. An equal amount of protein $(50 \mu \mathrm{g})$ was subjected to electrophoresis and was then transferred to nitrocellulose membranes (Schleicher \& Schuell Inc., Keene, NH, USA). Each one of the nitrocellulose stains was washed twice in phosphate-buffered saline (PBS) for $5 \mathrm{~min}$ and then blocked with $1 \%$ cattle serum albumin in
PBS for $1 \mathrm{~h}$ before administration of the primary antibody. Antibodies against NF- $\mathrm{B}, \mathrm{HO}-1, \mathrm{Nrf}-2$, TNF- $\alpha$, COX-2, IL-10, and IL- 6 were procured from Santa Cruz Biotechnology, Inc. (Santa Cruz, CA, USA). The antibody against AP-1 was procured from Abcam (Cambridge, United Kingdom). The primary antibody was diluted in the same buffer containing $0.05 \%$ Tween-20 (1 : 1000). The nitrocellulose membrane was incubated with protein antibody at $4^{\circ} \mathrm{C}$ for the whole night.

The blots were washed and incubated with horseradish peroxidase conjugated goat antimouse IgG (Abcam, Cambridge, England). Specific bonding was identified through the use of such substrates as diaminobenzidine and $\mathrm{H}_{2} \mathrm{O}_{2}$. The protein load was checked with a monoclonal mouse antibody against $\beta$-actin antibody (A5316; Sigma). Blots were utilised at least three times with a view to confirming the repeatability of results. These were analysed in terms of the measurement of density through the use of an image analysis system (Image J; National Institute of Health, Bethesda, MD, USA).

\section{Histopathological findings}

Distal colon segments were fixed in $10 \%$ phosphate-buffered formaldehyde, immersed in wax, and sliced into cross-sections of $5 \mu \mathrm{m}$. These cross-sections were dyed with haematoxylin and eosin for light microscopic examination. The tissue pieces were screened and scored by a specialised pathologist who had not seen and was not aware of the experimental groups.

Each tissue specimen on a glass slide was evaluated under a light microscope at 200× magnification. Each microscopic area was evaluated and scored. In the presence of multiple scores in any field of view, average scores were calculated for 
Table II. Histological scoring of colon specimens stained with haematoxylin-eosin

\begin{tabular}{|c|c|}
\hline Score & Definition \\
\hline 0.0 & Normal colonic mucosa \\
\hline 1.0 & Loss or shortening of the basal $1 / 3$ of the crypts \\
\hline 2.0 & Loss of the basal $2 / 3$ of the crypts \\
\hline 3.0 & $\begin{array}{l}\text { Total crypt loss but epithelial surface of the lamina propria remains intact and submucosa shows mild } \\
\text { inflammatory cell infiltration }\end{array}$ \\
\hline 3.5 & $\begin{array}{l}\text { Total crypt loss but epithelial surface of the lamina propria remains intact and submucosa shows severe } \\
\text { inflammatory cell infiltration }\end{array}$ \\
\hline 4.0 & Erosion and marked cellular infiltration \\
\hline
\end{tabular}

such fields. Classification was secured on the basis of previously defined scoring criteria [13].

Histological scoring: For each specimen, damage characteristics were identified through the examination of such properties as sub-mucosal oedema, damage/necrosis, inflammatory cell infiltration, vasculitis, perforation, total crypt loss, and degree of intestinal damage (Table II) [14].

\section{Statistical analysis}

The data were presented as average \pm standard deviation. The sample size was calculated according to power analysis at $85 \%$ and the $p$-value was calculated as 0.05 . the differences among groups were evaluated through the use of one-way analysis of variance (ANOVA) and Tukey's post hoc test (SAS Institute: SAS 2002, User's Guide: Statistics). The value of $p<0.05$ was considered significant.

\section{Results}

Haemorrhagic diarrhoea developing $24 \mathrm{~h}$ after the administration of AA was observed in all groups only on the day following $A A$ management, but did not continue. One rat in the AA + WPI group and 2 rats in the AA + WPII group died (the rat which was examined exhibited colon perforation, while the cause of death could not be determined for the other two rats).

\section{Western blot analysis}

The effects of whey protein on AP-1, COX-2, HO-1, IL-6, IL-10, NF- $\kappa$ B, Nrf2, and TNF- $\alpha$ expressed in colon tissue are shown in Figure 2 and Table III following the Western blot method.

In comparison with the control group, AP-1, COX-2, IL-6, IL-10, NF- $\kappa$ B, and TNF- $\alpha$ had increased significantly among the rats in the ulcerative colitis group (Table III, Figures $2 \mathrm{~A}-\mathrm{F})(p<0.05)$. On the other hand, AP-1, COX-2, IL-6, IL-10, NF- $\mathrm{B}$ levels had decreased along with both WPI and WPII treatments when compared with the UC group and the WPII (double dose a day) treatment had allowed for the decrease thereof to levels comparable with the control group, while the WPI treat- ment had allowed the same to remain significantly high in comparison to the control group. When compared with the UC group, COX-2 and IL-10 levels had decreased significantly only upon the WPII treatment to levels comparable with those in the control group (Table III, $p<0.05$ ). WPI treatment had not led to a significant decrease compared to the AA group, whereas it was identified to have remained significantly high in comparison to the control group. When compared with the UC group, TNF- $\alpha$ level had decreased significantly only upon both WPI and WPII treatment to levels comparable with those in the control group $(p=0.001)$.

In comparison with the control group, HO-1 and Nrf-2 had decreased significantly among the rats in the UC group (Table III, Figures $2 \mathrm{G}, \mathrm{H}$ ) $(p<0.05)$. WP treatment had caused an increase in the HO-1 level in both treatment groups, yet such an increase only reached a level comparable with that in the control group in the WPI group. A comparison with the UC group indicated a significant increase in the Nrf-2 level as a result of WPI-WPII treatment $(p<0.05)$; however, this increase was significantly smaller than that in the control group.

\section{Histopathological findings}

The administration of AA had resulted in UC and caused marked inflammation, necrosis, and fibrosis. The average scores of groups in histopathological examination (Table IV) were as follows: control group: 0, AA group: $3, A A+W P I$ group: 3.17, AA + WPI group: 3.1. The administration of a single dose and a double dose had not led to any significant histopathological improvement (Table IV, $p>0.05$ ).

\section{Discussion}

Regardless of the mechanism responsible for the onset and maintenance of intestinal inflammation, there is an intensive local immune response concerning lymphocytes and macrophages. The release of soluble cytokines and other inflammatory mediators causes tissue damage, which, in turn, contributes to the exacer- 
A
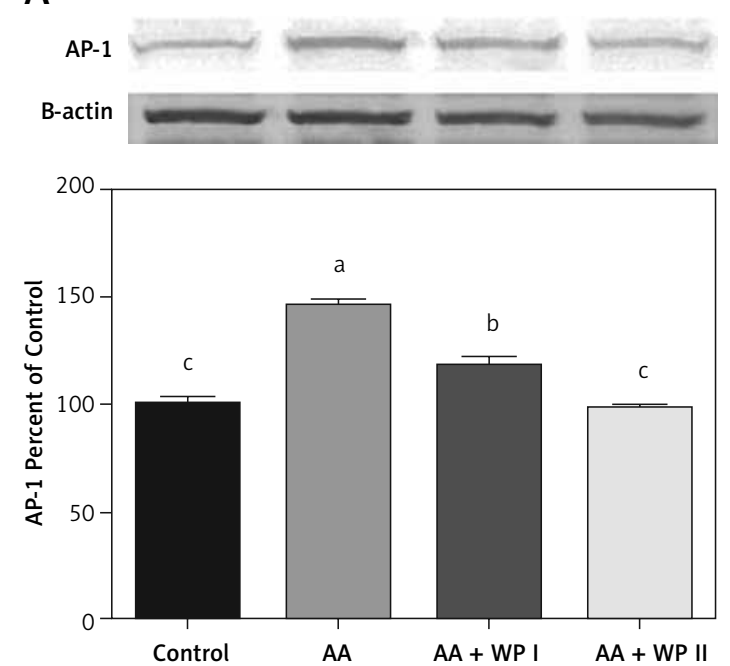

C
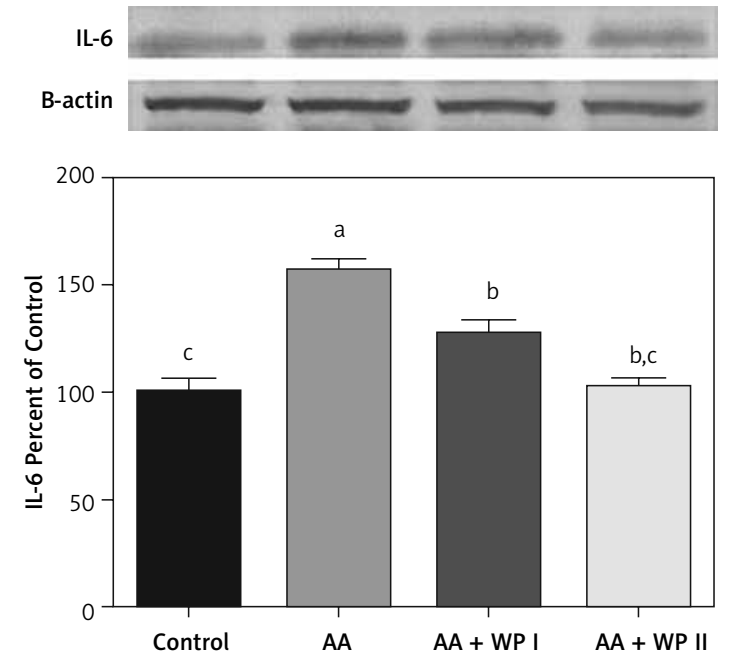

$E$
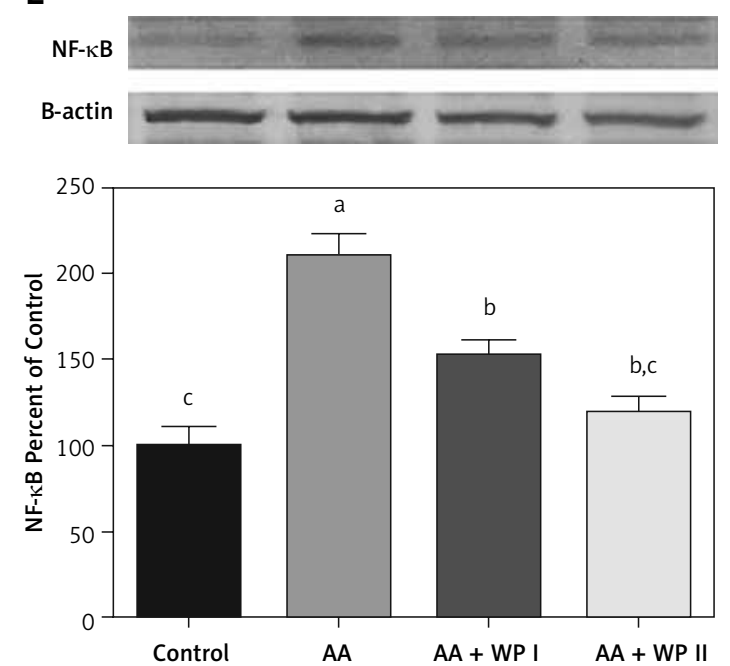

B
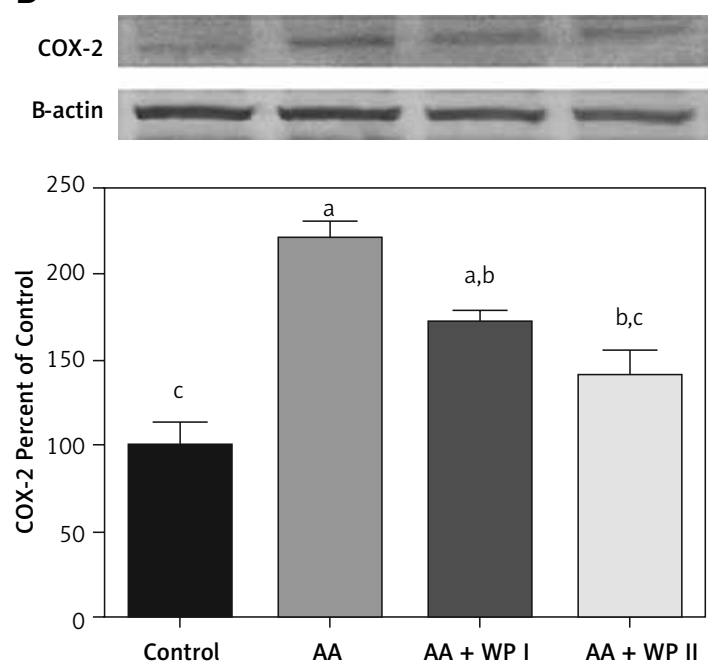

D
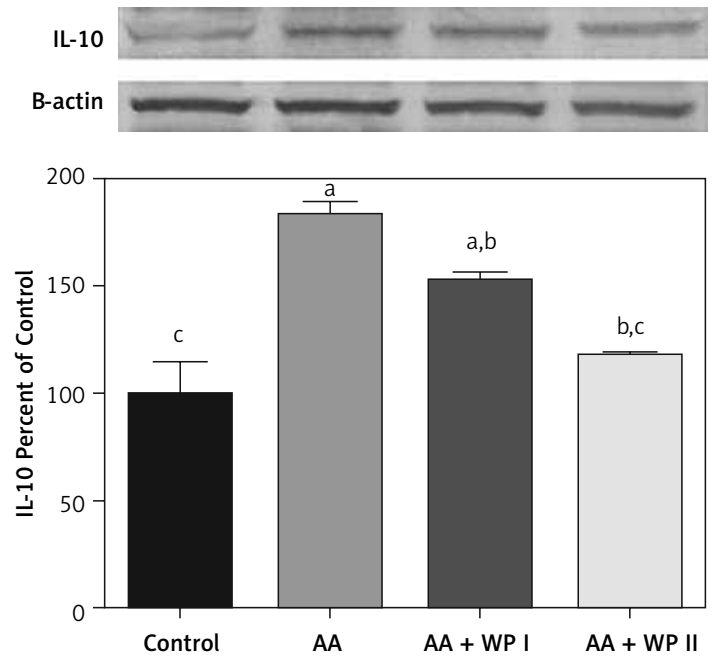

$\mathrm{F}$
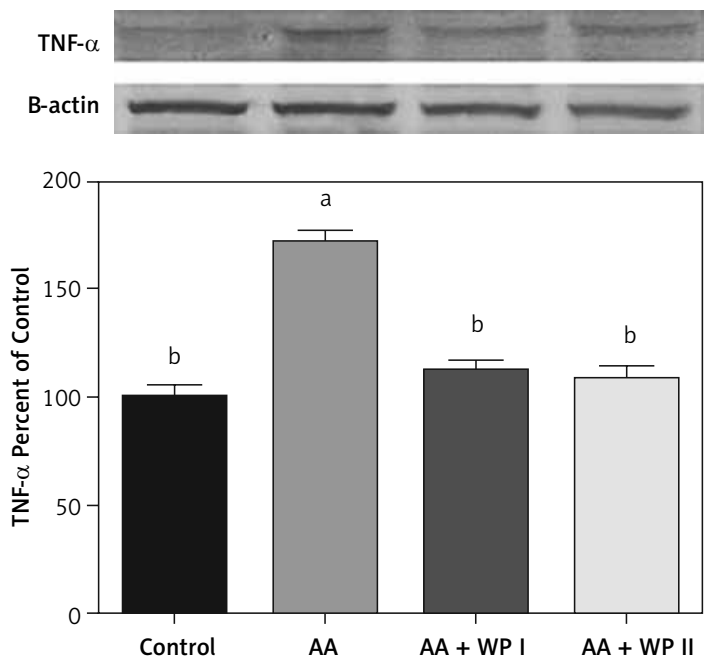

Figure 2. Effects of whey protein on colon tissue in acetic acid-induced colitis model in rats. The intensity of the bands was quantified by densitometric analysis and $\beta$-actin was included to ensure equal protein loading. Data are expressed as a ratio of the normal control value (set to $100 \%$ ). Each bar represents the mean and standard error. Blots were repeated at least 3 times $(n=3)$. Different superscripts on top of each bar $(a-c)$ indicate group mean differences. Superscripts ${ }^{a-c}$ indicate that means in the same row without a common superscript differ significantly $(p<0.05)$ 
G
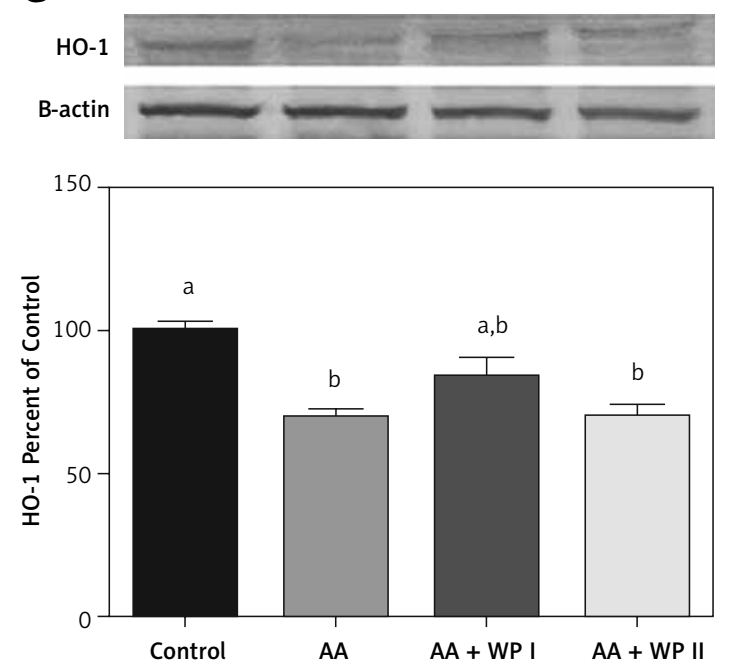

$\mathrm{H}$
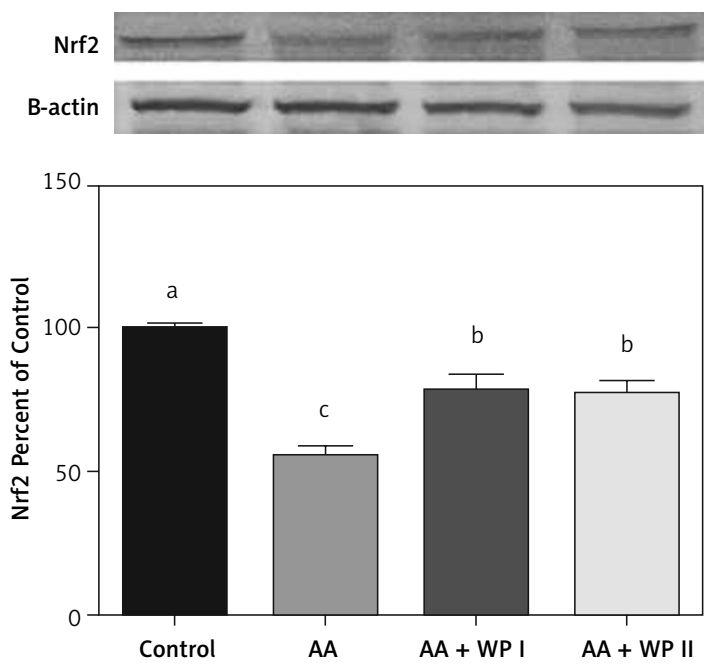

Figure 2. Cont.

Table III. Effects of whey protein on colon tissue and $p$-values. The data are given as mean and standard deviation. Superscripts ${ }^{\mathrm{a}-c}$ indicate that means in the same row without a common superscript differ significantly. Data in bold indicate statistical significance at $p<0.05$

\begin{tabular}{|c|c|c|c|c|c|c|c|c|}
\hline \multirow[t]{2}{*}{ Items } & \multicolumn{8}{|c|}{ Groups } \\
\hline & \multicolumn{2}{|c|}{ Control } & \multicolumn{2}{|c|}{ AA } & \multicolumn{2}{|c|}{$A A+W P I$} & \multicolumn{2}{|c|}{ AA + WPII } \\
\hline AP-1 & \multicolumn{2}{|c|}{$100.00 \pm 3.01^{c}$} & \multicolumn{2}{|c|}{$145.97 \pm 2.81^{\mathrm{a}}$} & \multicolumn{2}{|c|}{$118.79 \pm 2.77^{b}$} & \multicolumn{2}{|c|}{$98.28 \pm 0.84^{c}$} \\
\hline COX-2 & \multicolumn{2}{|c|}{$100.00 \pm 14.12^{c}$} & \multicolumn{2}{|c|}{$220.78 \pm 10.65^{a}$} & \multicolumn{2}{|c|}{$172.06 \pm 7.15^{\mathrm{ab}}$} & \multicolumn{2}{|c|}{$141.42 \pm 14.93^{\mathrm{bc}}$} \\
\hline Nrf2 & \multicolumn{2}{|c|}{$100.00 \pm 1.86^{a}$} & \multicolumn{2}{|c|}{$55.59 \pm 3.10^{c}$} & \multicolumn{2}{|c|}{$78.27 \pm 5.67^{b}$} & \multicolumn{2}{|c|}{$77.14 \pm 4.89^{b}$} \\
\hline $\mathrm{HO}-1$ & \multicolumn{2}{|c|}{$100.00 \pm 2.61^{a}$} & \multicolumn{2}{|c|}{$69.43 \pm 2.87^{b}$} & \multicolumn{2}{|c|}{$84.12 \pm 6.04^{\mathrm{ab}}$} & \multicolumn{2}{|c|}{$70.40 \pm 3.64^{b}$} \\
\hline IL-6 & \multicolumn{2}{|c|}{$100.00 \pm 6.43^{c}$} & \multicolumn{2}{|c|}{$156.66 \pm 5.67^{a}$} & \multicolumn{2}{|c|}{$127.11 \pm 5.96^{b}$} & \multicolumn{2}{|c|}{$102.00 \pm 4.36^{b c}$} \\
\hline IL-10 & \multicolumn{2}{|c|}{$100.00 \pm 14.67^{c}$} & \multicolumn{2}{|c|}{$183.20 \pm 6.70^{a}$} & \multicolumn{2}{|c|}{$152.76 \pm 4.00^{\mathrm{ab}}$} & \multicolumn{2}{|c|}{$117.78 \pm 1.61^{b c}$} \\
\hline$N F-\kappa B$ & \multicolumn{2}{|c|}{$100.00 \pm 10.63^{c}$} & \multicolumn{2}{|c|}{$210.04 \pm 12.43^{a}$} & \multicolumn{2}{|c|}{$152.52 \pm 8.38^{b}$} & \multicolumn{2}{|c|}{$119.41 \pm 9.87^{b c}$} \\
\hline \multirow[t]{2}{*}{ TNF- $\alpha$} & \multicolumn{2}{|c|}{$100.00 \pm 5.96^{b}$} & 172 & $4.53^{\mathrm{a}}$ & 112 & $=4.61^{\mathrm{b}}$ & 108 & $=5.63^{b}$ \\
\hline & AP-1 & COX-2 & HO-1 & IL-6 & IL-10 & NF-אB & Nrf2 & TNF- $\alpha$ \\
\hline Control-AA & 0.001 & 0.001 & 0.003 & 0.001 & 0.001 & 0.001 & 0.001 & 0.001 \\
\hline Control-WP-1 & 0.003 & 0.013 & 0.089 & 0.038 & 0.009 & 0.030 & 0.025 & 0.383 \\
\hline Control-WP-2 & 0.961 & 0.150 & 0.004 & 0.994 & 0.447 & 0.579 & 0.019 & 0.675 \\
\hline AA-WP-1 & 0.001 & 0.083 & 0.120 & 0.025 & 0.120 & 0.019 & 0.020 & 0.001 \\
\hline AA-WP-2 & 0.001 & 0.007 & 0.998 & 0.001 & 0.002 & 0.001 & 0.026 & 0.001 \\
\hline WP-1-WP-2 & 0.002 & 0.344 & 0.152 & 0.055 & 0.070 & 0.191 & 0.997 & 0.942 \\
\hline
\end{tabular}

$A A$ - acetic acid, $A A+W P I-$ acetic acid and single dose whey protein, $A A+$ WPII - acetic acid and double dose whey protein group per day, $A P-1$ - active protein kinase-1, COX-2 - cyclooxygenase-2, HO-1 - haemoxygenase-1, IL-6, 10 - interleukin-6, 10, NF- $\mathrm{K} B$ - nuclear factor $\kappa B, N r f-2$ - nuclear related factor-2, TNF- $\alpha$-tumour necrotizing factor- $\alpha$.

Table IV. Histopathological effects of whey protein on colonic tissue in acetic acid induced ulcerative colitis model in rats. Histopathological scoring of the groups [12]. Data are means and standard error. Superscripts ${ }^{a-c}$ indicate that means in the same row without a common superscript differ significantly

\begin{tabular}{|lcccc|}
\hline & \multicolumn{4}{c|}{ Groups } \\
\cline { 2 - 5 } & Control & AA & AA + WP1 & AA + WP2 \\
\hline Score & $0.00 \pm 0.00^{\mathrm{b}}$ & $3.00 \pm 0.42^{\mathrm{a}}$ & $3.17 \pm 0.11^{\mathrm{a}}$ & $3.10 \pm 0.53^{\mathrm{a}}$ \\
\hline
\end{tabular}


bation and continuation of the local inflammatory response [14]. For the purposes of the present study, UC was induced in rats with an AA dose of $5 \%$. The histopathological examination identified marked necro-inflammation and fibrosis in rats treated with $A A$. However, the significant increases observed in the levels of AP-1, COX-2, IL-6, IL-10, NF- $\kappa B$, and TNF- $\alpha$, i.e. inflammation markers relevant to the development of UC, had decreased significantly and to levels similar to those in the control group along with the whey protein treatment. On the other hand, we identified that the development of UC decreased the Nrf2-ARE (antioxidant releasing element) signal pathway and $\mathrm{HO}-1$ protein, which both have protective roles in the colon inflammatory response, while whey protein activated the Nrf2-HO-1 pathway.

Nrf2 and INrf2 (Keap1) are the cellular sensors of oxidative stress. Nrf2 controls the expression and coordination of a series of defence genes coding detoxifying enzymes and antioxidant proteins [15]. The activation of Nrf2 may lead to a decrease in the induction of antioxidative genes and the synthesis of pro-inflammatory mediators [16]. Therefore, the impairment and loss of the Nrf2 signal pathway gives way not only to oxidative and electrophilic stresses, but also to an increase in sensitivity towards inflammatory tissue damage. The protective role assumed by the Nrf2-ARE signal pathway in colitis was examined through the use of Nrf2-ARE knock-out mice exhibiting severe inflammatory symptoms [17]. In addition, recent studies have shown the role Nrf2-ARE signalling plays in the decrease of pathogenesis relating to inflammation in various diseases including colitis [18]. The present study revealed that the Nrf2 expression in the colon had decreased markedly along with the administration of AA and increased significantly along with the rectal administration of a single dose of whey protein. There was no significant difference between WPI and WPII in terms of the increase in Nrf2.

The control of HO-1 expression is realised at the transcription level and mediated by such different transcription factors as NF- $\mathrm{KB}$ and Nrf2 [19]. Among the enzymes regulated by Nrf2, HO-1 also exhibits an antioxidative feature in addition to its anti-inflammatory effect. In addition, HO-1 is a critical regulator for innate immunity and the modulation of inflammation and has been identified to increase in response to acute inflammatory diseases. HO-1is an inducible protein responsible for host defence against intestinal inflammation $[20,21]$. The expression of HO-1 protein has been established to increase in the colonic mucosa of patients with active UC [22]. In addition, any increase in $\mathrm{HO}-1$ is protective against an inflammatory response in the colon [22]. Within the course of the present study, the administration of $A A$ increased the significantly lower HO-1 although not to a significant extent.

Other redox-sensitive transcription factors activated with oxidative stress are NF- $\mathrm{KB}$ and AP-1. These transcription factors play an important regulatory role in $\mathrm{HO}-1$ gene induction [23]. AP-1 is another redox-regulating transcription factor that plays a role in the regulation of inflammation-mediated cellular functions. In addition, granulocytes and macrophages in inflammation zones generate highly pro-inflammatory cytokines including IL- 6 and TNF- $\alpha$ that play a direct role in the pathogenesis of IBD $[24,25]$. With respect to all proteins specified in the present study, AP-1, IL-6, IL-10, NF- $\kappa B$, TNF- $\alpha$ levels increased along with the AA induced colonic injury and led to inflammation. However, whey protein decreased the tissue level of such proteins at a significant level. This decrease in AP-1, IL-6, IL-10, and NF- $\kappa$ B levels is at a significant level in the WPI group with no significant difference observed between WPII and control groups. The study did not detect a significant difference between WPI and control groups in terms of TNF- $\alpha$ level. In the light of such data, the inhibition of AP-1 appears to be a promising therapeutic strategy to decrease inflammatory cytokines and chemokines that play an important role in the treatment of inflammatory diseases.

COX-2 is also regulated through redox-sensitive transcription factors activated in the presence of the oxidative system and the generation of COX-2 is up-regulated by redox-sensitive transcription factors in inflammation zones [25-27]. The increase in intestinal inflammation was shown to lead to up-regulation of COX-2 [28-30]. The present study established COX-2 expression in the rat colon to increase significantly due to the administration of AA. Whey protein created a significant decrease in the expression of COX-2 induced by AA damage. While COX-2 decreased significantly along with the WPI treatment, the difference between WPII and control groups receded to undetectable levels.

When considered in combination, the administration of whey protein prevented and treated the increased expression of the aforementioned mediators including AP-1, NF- $\mathrm{B}$, TNF- $\alpha, \mathrm{IL}-6, \mathrm{IL}-10$, and $\mathrm{COX}-2$ to a significant degree in colon damage induced by AA. The increase in the expressions of Nrf2 and HO-1 arising from the administration of whey protein indicates that the beneficial effects of this agent is achieved at least through the activation of the Nrf2-HO-1 pathway. The activation of Nrf2-ARE at an early stage in the inflammation-mediated tissue damage may inhibit the generation or expression of pro-inflammatory mediators including cytokines, chemokines, cell 
adhesion molecules, matrix metalloproteinases, COX-2, and inducible nitric oxide synthase. The cytoprotective function of the genes targeted by Nrf2 is considered also to be able to regulate the innate immune response cooperatively and to suppress the induction of pro-inflammatory genes [31]. The findings of the present study indicated that whey protein activated the Nrf2-HO-1 pathway. Nrf2 increased to a statistically significant extent, while HO-1 did increase although not to such an extent.

The rectal administration of whey protein was observed not to treat UC in histopathological terms despite its aforementioned positive effects. The reason behind the lack of histopathological improvement in either dosage may be the short duration allocated for the experiment (7 days). Therefore, a study aiming to observe positive histopathological effects may need to administer whey protein for a longer period of time, i.e. 2 or 4 weeks. There is a need for studies implementing treatments of different (higher) lengths rather than different dosages.

Consequently, whey protein offers therapeutic effects against colonic inflammation induced by AA through its antioxidative and anti-inflammatory effects and its modulation of $\mathrm{Nrf} 2 / \mathrm{HO}-1$ and NF- $\kappa B$ pathways as important factors to decrease pro-inflammatory signalling and colonic inflammatory cell infiltration.

The activation of Nrf2 supports the restoration of balance between oxidants and antioxidants and plays a central role in the efforts to increase the expression of antioxidant genes such as HO-1.

\section{Acknowledgments}

This study was supported by Firat University Scientific Research Projects Unit with Project number TF.17.11. The authors are grateful to the Department of Gastroenterology and Department of Pathology, School of Medicine, Firat University, for their valuable support.

\section{Conflict of interest}

The authors declare no conflict of interest.

\section{References}

1. Kawalec P. Indirect costs of inflammatory bowel diseases: Crohn's disease and ulcerative colitis. A systematic review. Arch Med Sci 2016; 12: 295-302.

2. Rachmilewitz D, Karmeli F, Okon E, Bursztyn M. Experimental colitis is ameliorated by inhibition of nitric oxide synthase activity. Gut 1995; 37: 247-55.

3. Pavlick KP, Laroux FS, Fuseler J, et al. Role of reactive metabolites of oxygen and nitrogen in inflammatory bowel disease. Free Radic Biol Med 2002; 33: 311-22.

4. Jiang H, Deng CS, Zhang M, Xia J. Curcumin-attenuated trinitrobenzene sulphonic acid induces chronic colitis by inhibiting expression of cycloo xygenase-2. World J Gastroenterol 2006; 12: 3848-53.

5. Millar AD, Rampton DS, Chander CL, et al. Evaluating the anti oxidant potential of new treatments for inflammatory bowel disease using a rat model of colitis. Gut 1996; 39: 407-15.

6. Bereswill S, Muñoz M, Fischer A, et al. Anti-inflammatory effects of resveratrol, curcumin and simvastatin in acute small intestinal inflammation. PLoS One 2010; 5: e15099.

7. Kawase M, Hashimoto $H$, Hosoda M, Morita H, Hosono $A$. Effect of administration of fermented milk containing whey protein concentrate to rats and healthy men on serum lipids and blood pressure. J Dairy Sci 2000; 83: 255-63.

8. Nguyen DN, Sangild PT, Li Y, Bering SB, Chatterton DE. Processing of whey modulates proliferative and immune functions in intestinal epithelial cells. J Dairy Sci 2016; 99: 959-69.

9. Kanwar JR, Kanwar RK. Gut health immuno modulatory and anti-inflammatory functions of gut enzyme digested high protein micro-nutrient dietary supplement-Enprocal. BMC Immunol 2009; 10: 7

10. U.S department of healt and human services food and drug administration center for drug evaluation and research (CDER). Guidance for Industry Estimating the Maximum Safe Starting Dose in Initial Clinical Trials for Therapeutics in Adult Healthy Volunteers. Pharmacology and toxicology July 2005.

11. Farombi EO, Shrotriya S, Na HK, Kim SH, Surh YJ. Curcumin attenuates dimethyl nitrosamine-induced liver injury in rats through Nrf2-mediated induction of heme oxygenase-1. Food Chem Toxicol 2008; 46: 1279-87.

12. Lowry OH, Rosebrough NJ, Farr AL, Randall RJ. Protein measurement with the folin phenol reagent. J Biol Chem 1951; 193: 265-75.

13. Li L, Ren F, Yun Z, An Y, Wang C, Yan X. Determination of the effects of lactoferrin in a preclinical mouse model of experimental colitis. Mol Med Rep 2013; 8: 1125-9.

14. Weldon MJ, Maxwell JD. Lymphocyte and macrophage interleukin receptors in inflammatory bowel disease: a more selective target for therapy? Gut 1994; 35: 867-71.

15. Kaspar JW, Niture SK, Jaiswal AK. Nrf2: INrf2 (Keap1) signaling in oxidative stress. Free Radic Biol Med 2009; 47: 1304-9.

16. Choi SH, Park S, Oh CJ, Leem J, Park KG, Lee IK. Dipeptidyl peptidase-4 inhibition by gemigliptin prevents abnormal vascular remodeling via NF-E2-related factor 2 activation. Vascular Pharmacol 2015; 73: 11-9.

17. Khor TO, Huang MT, Kwon KH, Chan JY, Reddy BS, Kong AN. Nrf2-deficient mice have an increased susceptibility to dextran sulfate sodium-induced colitis. Cancer Res 2006; 66: 11580-4.

18. Kim J, Cha YN, Surh YJ. A protective role of nuclear factor-erythroid 2-related factor-2 (Nrf2) in inflammatory disorders. Mutat Res 2010; 690: 12-23.

19. Ferrandiz ML, Devesa I. Inducers of heme oxygenase-1. Curr Pharm Des 2008; 14: 473-86.

20. Wang WP, Guo X, Koo MW, et al. Protective role of heme oxygenase- 1 on trinitrobenzene sulfonic acid-induced colitis in rats. Am J Physiol Gastrointest Liver Physiol 2001; 281: G586-94.

21. Naito Y, Takagi T, Yoshikawa T. Heme oxygenase-1: a new therapeutic target for inflammatory bowel disease. Aliment Pharmacol Ther 2004; 20: 177-84.

22. Horváth K, Varga C, Berkó A, Pósa A, László F, Whittle BJ. The involvement of heme oxygenase-1 activity in the 
therapeutic actions of 5-aminosalicylic acid in rat colitis. Eur J Pharmacol 2008; 581: 315-23.

23. Farombi EO, Surh YJ. Heme oxygenase-1 as a potential therapeutic target for hepatoprotection. J Biochem $\mathrm{Mol}$ Biol 2006; 39: 479-91.

24. Angel P, Karin M. The role of Jun, Fos and the AP-1 complex in cell-proliferation and transformation. Biochim Biophys Acta 1991; 1072: 129-57.

25. Ryseck RP, Bravo R. c-JUN, JUN B, and JUN D differ in their binding affinities to AP-1 and CRE consensus sequences: effect of FOS proteins. Oncogene 1991; 6: 533-42.

26. Tsujii M, Kawano S, Tsuji S, Sawaoka H, Hori M, DuBois RN. Cyclooxygenase regulates angiogenesis induced by colon cancer cells. Cell 1998; 93: 705-16.

27. Wang D, Dubois RN. The role of COX-2 in intestinal inflammation and colorectal cancer. Oncogene 2010; 29: 781-8.

28. Hwang YP, Choi JH, Yun HJ, et al. Anthocyanins from purple sweet potato attenuate dimethylnitrosamine-induced liver injury in rats by inducing Nrf2-mediated anti oxidant enzyme sand reducing COX-2 and iNOS expression. Food Chem Toxicol 2011; 49: 93-9.

29. Ancha HR, Kurella RR, McKimmey CC, Lightfoot S, Harty RF. Effects of $\mathrm{N}$-acetyl cysteine plus mesalamine on prostaglandin synthesis and nitric oxide generation in TNBS-induced colitis in rats. Dig Dis Sci 2009; 54: 758-66.

30. Dudhgaonkar SP, Tandan SK, Kumar D, Raviprakash V, Kataria M. Influence of simultaneous inhibition of cyclooxygenase-2 and inducible nitric oxide synthase in experimental colitis in rats. Inflammopharmacology 2007; 15: 188-95.

31. Jaiswal AK. Nrf2 signaling in coordinated activation of antioxidant gene expression. Free Radic Biol Med 2004; 36: 1199-207. 